\title{
Influence of Myeloperoxidase Levels on Periodontal Disease: An Applied Clinical Study
}

\author{
Alessandro Polizzi *(D), Salvatore Torrisi, Simona Santonocito, Mattia Di Stefano, \\ Francesco Indelicato and Antonino Lo Giudice $\mathbb{D}$
}

Department of General Surgery and Surgical-Medical Specialties, School of Dentistry, University of Catania, AOU Policlinico-P.O. Vittorio Emanuele, Via Plebiscito 628, 95124 Catania, Italy; ture_torrisi@hotmail.it (S.T.); simonasantonocito.93@gmail.com (S.S.); mattiadistefano@live.it (M.D.S.); indelicato@policlinico.unict.it (F.I.); nino.logiudice@gmail.com (A.L.G.)

* Correspondence: alexpoli345@gmail.com; Tel./Fax: +39-0957435359

Received: 26 January 2020; Accepted: 3 February 2020; Published: 4 February 2020

\begin{abstract}
In this trial, we evaluated the influence on plasma and salivary myeloperoxidase (MPO) levels of periodontal health, coronary heart disease (CHD), periodontitis, or both periodontitis and CHD. Clinical and periodontal parameters were collected from periodontitis patients $(n=31)$, CHD patients $(n=31)$, patients with both periodontitis and CHD $(n=31)$, and from healthy patients $(\mathrm{n}=31)$ together with saliva and plasma samples. The median concentrations of salivary and plasma MPO were statistically higher in the CHD patients [plasma: 26.2 (18.2-34.4) ng/mg; saliva $83.2(77.4-101.5) \mathrm{ng} / \mathrm{mL}, \mathrm{p}<0.01$ ] and in the periodontitis plus CHD patients [plasma: $27.8(22.5-35.7)$ $\mathrm{ng} / \mathrm{mg}$; saliva $85.6(76.5-106.7) \mathrm{ng} / \mathrm{mL}, \mathrm{p}<0.001]$ with respect to periodontitis and control patients. Through a univariate regression analysis, c-reactive protein (CRP) and CHD (both $\mathrm{p}<0.001$ ) and periodontitis $(\mathrm{p}=0.024)$ were statistically correlated with MPO in plasma. The multivariate regression analysis demonstrated that only CRP was statistically the predictor of MPO in plasma ( $\mathrm{p}<0.001)$. The multivariate regression analysis in saliva demonstrated that, regarding MPO levels the only predictors were CRP $(p<0.001)$ and total cholesterol $(p=0.035)$. The present study evidenced that subjects with CHD and periodontitis plus CHD had higher plasma and salivary levels of MPO compared to subjects with periodontitis and healthy controls.
\end{abstract}

Keywords: myeloperoxidase; periodontitis; cardiovascular disease; applied model

\section{Introduction}

Periodontal disease is a common oral inflammatory multifactorial disease that causes the disruption of the periodontium and the tissues that support the tooth, such as bone and cementum main caused by oral bacteria, that ultimately leads to the loss of the tooth [1]. Almost all adults in the USA present periodontal disease forms and nearly ten percent of the population worldwide express severe type of periodontal disease [2,3].

More recently, observational reports have shown a correlation between periodontal disease and cardiovascular disease, such as stroke, heart disease and endothelial dysfunction $[4,5]$. Moreover, some studies demonstrated a specific correlation among periodontal disease and an augmented risk of stroke [6] and, coronary heart disease (CHD) [7,8].

The pathogenesis of periodontal disease includes inflammatory and bacteria responses which may determine an increased host response subsequent to the presence of pathogenic oral biofilm in gingival tissues [9]. More specifically, periodontal disease has been correlated with an increase of levels of some systemic inflammatory mediators in serum, such as prostaglandin, interleukin 1 (IL-1), IL-6, and C-reactive protein (CRP) [10]. 
Myeloperoxidase (MPO) is one of the more mediators expressed within tissues during the progression of inflammation [11]. It was demonstrated that MPO, secreted by endothelial cells after exposure to pathogenic bacteria, represents a potent mediator of vascular inflammation and a vasoconstrictor [12].

In this regard, it has been shown that several proinflammatory cytokines, including IL-1, -6 , and -8 , have been reported to upregulate the secretion of MPO [13]. The expression of MPO was strongly associated in the gingival tissue and endothelial cells during periodontitis [14]. More specifically, a clinical study found that, in gingival crevicular fluid, MPO increased with the progression of the periodontitis, and also that MPO was involved in the regulation of IL-1b expression in gingival tissues $[15,16]$.

During the last few decades, several studies have analyzed the association between periodontal disease endothelial dysfunction, and increased risk of CHD and cardiovascular disease (CVD) $[17,18]$. More specifically, it has been supposed that the inflammatory mediators that are present and released during the active phase of periodontal disease such as CRP, interleukins, prostaglandins, and metalloproteases, can negatively influence the release of nitric oxide (NO) [19]. The altered release of NO can affect the endothelium which in turn regulates vascular tone, and, finally, dysfunction of the endothelium and enhanced risk of CVD [20,21]. For these causes, there is growing interest to investigate some other oral mediators that can regulate and impact the subclinical endothelial dysfunctions as an early sign of augmented risk of CHD and CVD. In this regard, a correlation between high proportion of MPO, CRP, and endothelial dysfunction was recently reported [22,23].

The production of NO at local level has been shown to be fundamental in the aetiology and progression of periodontitis. The increment and reduction of NO metabolites in saliva production in periodontal tissue against periodontopathogenic microbiota during periodontitis have been demonstrated to be correlated endothelial dysfunction [24,25]. Furthermore, it has been reported that MPO plays an important role in the reduction of NO synthase especially during periodontitis [26].

Based on these findings, the aims of this trial were to consider a possible association of periodontitis, CVD, or both periodontitis plus CVD on serum and salivary MPO. Futhermore, we analyzed the possible correlation between MPO in serum and saliva and if serum CRP mediated the association between salivary or serum MPO levels.

\section{Materials and Methods}

\subsection{Study Design}

For the present study, 311 healthy controls and patients with periodontitis or CHD were chosen at the School of Odontostomatology of the University of Catania, Italy, from October 2018 to December 2019. Patients were chosen in a specific range of age (35-65 years old) and on gender in order to have similar proportion of patients in each category characterized by the selection variable. $50 \%$ of the patients and controls were males with $45-54$ year of age.

The study was performed following the 2016 revision of the Helsinki declaration on medical research. Ethical approval was obtained by the local International Review Board (IRB) (\#18-18). The study was registered at clinicaltrials.gov (NCT04152023). An informed written consent was obtained from each enrolled patient. The trial was performed in accordance to the guidelines for the strengthening of reporting of observational studies (STROBE) [27].

The inclusion criteria for the subjects enrolled in the periodontitis group were: (1) at least 16 teeth, (2) at least of $40 \%$ of periodontal sites with clinical attachment level (CAL) $\geq 2 \mathrm{~mm}$ and probing depth (PD) $\geq 4 \mathrm{~mm}$ [28]; (3) at least one periodontal site with $\geq 2 \mathrm{~mm}$ of crestal alveolar bone loss confirmed on digital periapical $x$-rays; (4) at least $\geq 40 \%$ sites with bleeding on probing (BOP) [29]. Healthy controls had any systemic disorder, at least $\leq 10 \%$ sites with BOP, and no periodontal sites with PD or CAL $\geq 4$ $\mathrm{mm}$, or $\mathrm{x}$-ray signs of bone loss. 
For the CVD group, the inclusion criteria were: at least $\geq 18$ years; a diagnosis of CVD with $\geq 50 \%$ of stenosis of at least one coronary artery verified by coronary angiography, or past or current percutaneous coronary intervention [30]. Each type of previous disease, taking drugs, or previous CVD exams (e.g., electrocardiography, etc.) were recorded. In all patients, the diagnosis of CVD was performed by the same operator from medical record information. For the periodontitis plus CVD subjects the inclusion criteria were the same of the single disease (periodontitis and CVD).

The exclusion criteria of all subjects, were (1) consumption of contraceptive drugs; (2) consumption of antibiotics, anti-inflammatory or immunosuppressive drugs during the three months previous the trial; (3) presence of gestation or suction; (4) intake of alcohol; (5) anesthetic allergy; (6) intake of nifedipine, hydantoin or cyclosporin a drugs; (7) any type of periodontal treatment in the three months before baseline.

Then, 187 subjects were left out from the study because they did not meet the inclusion criteria $(n=129)$, failed to join in the study $(n=37)$, or were lost at the first assessment $(n=21)$. For these reasons, for the present study, 31 healthy subjects, 31 periodontitis patients, 31 CHD patients, and 31 patients with both diseases (periodontitis plus CHD) were enrolled in the end (Figure 1).

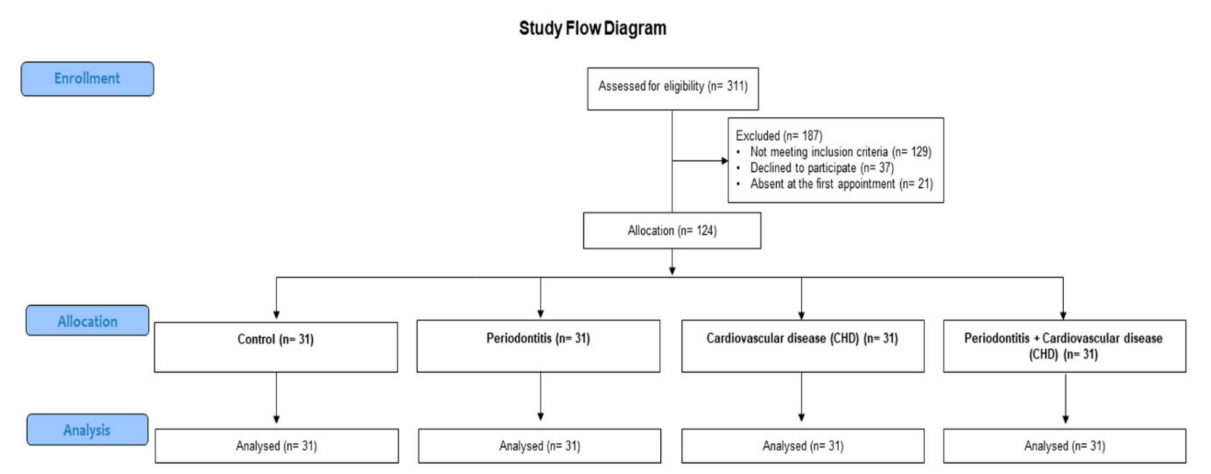

Figure 1. Flowchart of the study.

In each patient, every demographic characteristic (such as educational level) and demographic indices such as age, gender, body mass index (BMI), diabetes and other systemic events were recorded together with the type of drug taken. Diabetes was recorded on the patient's medical story or on fasting blood glucose $\geq 125 \mathrm{mg} / \mathrm{dL}$. The BMI was recorded by calculating the patient's weight divided by the square of his height in $\mathrm{kg} / \mathrm{m}^{2}$. All enrolled subjects were also classified on their smoking history, such as normal smokers, ex-smokers (subjects who have not smoked for $\geq 5$ years), and non-smokers.

The periodontal evaluation comprised clinical attachment loss (CAL), probing depth (PD), bleeding on probing (BOP), and plaque score (PI) [31]. CAL was verified, such as PD plus gingival recession using the cementoenamel junction as a reference. All periodontal indexes were registered, in all patients, by two independent calibrated examiners (a principal examiner and a control examiner), exonerated in the subsequent study steps, using a periodontal probe (UNC-15, Hu-Friedy, Chicago, IL, USA).

It was assessed the inter- and intra-examiner reliability for PD and CAL through the Intraclass Correlation Coefficient (ICC) analysis. The obtained inter-examiner reliability was in agreement for PD (ICC $=0.819)$ and CAL (ICC $=0.832$ ) with a good degree of reliability. The intra-examiner reliability of PD and CAL was done only on 24 subjects (six random subjects per group) for both examiners. For the first examiner, the intra-examiner reliability presented an agreement for PD $(I C C=0.819)$ and CAL (ICC $=0.808$ ); for the second examiner, the intra-examiner reliability was good for both PD (ICC $=0.818)$ and CAL $($ ICC $=0.801)$. All periodontal indexes were registered, in each enrolled subject, at six sites in each tooth.

A power analysis was executed in order to evaluate the sample size needed for the study. The sample size was determined considering four groups: an effect size of 0.29 for MPO (primary outcome chosen), a two-sided significance level of 0.05 , a standard deviation of 1.5 [23], and a power 
level of $80 \%$. It was established that would be required around 28 patients per group, with a total number of 114 patients required to obtain a power level of $80 \%$. a total of 124 patients were enrolled, so the study power was $81 \%$. Power and sample size calculation was performed with statistical software (G*Power version 3.1.9.4, Universitat Dusseldorf, Germany).

\subsection{Evaluation of Salivary and Serum MPO}

All serum and saliva samples were collected on an in all patients between 8:00 and 10:00 a.m., before the periodontal examination, on the same day by the same examiner. All enrolled subjects were requested to refrain from drinking, eating, chewing, brushing their teeth, or other oral hygiene maneuvers in the $12 \mathrm{~h}$ preceding the sampling of serum and saliva.

For the collection of serum, a venous blood sample was taken which, after the collection, was immediately cooled with ice and centrifuged at $4{ }^{\circ} \mathrm{C}(800 \times g$ for $10 \mathrm{~min})$. For the collection of saliva samples, the enrolled patients were asked to moisten by chewing a cotton roll for two minutes using the salivette method (Sarsted, Verona, Italy). Subsequently, the saliva sample in each patient was instantaneously centrifuged at $4{ }^{\circ} \mathrm{C}(1000 \times g$ for $2 \mathrm{~min})$. Both saliva and serum samples were stored at $-20^{\circ} \mathrm{C}$.

Magnetic bead-based luminex assay (R\&D Systems, Minneapolis, MN, and Sigma-Aldrich, Saint Louis, MO, USA) were used to detect serum and salivary concentrations of MPO, following the manufacturers' instructions. Levels of hs-CRP were calculated using a nephelometric assay kit. Levels of hs-CRP $>3 \mathrm{mg} / \mathrm{L}$ were related to an augmented CVD risk. Routine methods were applied to assess glucose and plasma lipids levels.

\subsection{Statistical Analysis}

Median, $25 \%$, and $75 \%$ percentile were used to express numerical variables while number and \% were used to express categorical variables. Nearly all of the variables analyzed (e.g., fasting glucose, triglycerides, all periodontal index) did not have normal distribution, as confirmed by Kolmogorov-Smirnov test. Only age, BMI, and salivary and serum MPO were normally distributed; for this reason, nonparametric tests were used to analyze all data in the present analysis [32]. More specifically, to confront all numerical variables in the 4 groups of patients, was applied the Kruskal Wallis test while the Mann Whitney test was applied to obtain the two-by-two comparisons. Bonferroni's correction was applied for numerous evaluations; the $\alpha$ level of 0.050 was split by the potential comparisons $(\mathrm{n}=6)$, and the adjusted significance level equalled $0.008(0.050 / 6)$.

The $p$-trend analysis for salivary and serum and MPO levels was obtained using the Jonckheere-Terpstra Test to evaluate whether MPO levels were statistically augmented in the four analyzed groups. To asses any significant interdependence between MPO in saliva and serum and hs-CRP, the Spearman correlation test was used.

Moreover, a univariate and multivariable linear regression analysis were applied in all enrolled patients to evaluate the dependence of MPO levels in serum and saliva (which resulted normally distributed) on possibly explicative outcomes such as sex, education, age, socioeconomic status (SES), triglycerides, total cholesterol, BMI, CRP, and CVD drugs (yes/no). In the multivariate final model, sex, age, and education SES were incorporated such as possible confounders, and tested to analyze if CHD, periodontitis, and hs-CRP influenced MPO in serum. For the evaluation of MPO in saliva, the same analysis was performed using salivary MPO levels as an outcome. All statistical analyses were executed using statistical software (SPSS 22.0 for Windows package, SPS srl, Bologna, Italy). a $p$-value $<0.05$ was set such as significant.

\section{Results}

The demographic and serological characteristics of the enrolled patients are shown in Table 1. All groups were matched for age and sex, and they did not presented any statistically significant differences regarding education levels, smoking, BMI, and serological features (Table 1). 
Table 1. Sample characteristics of enrolled patients. Data are represented as median (25th; 75th percentiles) or number with percentage. ${ }^{*} p<0.001$ and ${ }^{* *} p<0.001$ significant differences vs. healthy subjects computed by the Mann Whitney test. $\$ \S p<0.001$ significant differences vs. periodontitis patients calculated by the Mann Whitney test. ${ }^{\#} p<0.008$ significant differences vs. coronary heart disease (CHD) patients calculated by the Mann Whitney test.

\begin{tabular}{|c|c|c|c|c|}
\hline & Controls $(\mathrm{N}=31)$ & Periodontitis $(\mathrm{N}=31)$ & CVD (N = 31) & Periodontitis + CVD $(\mathrm{N}=31)$ \\
\hline Age (years) & $52(48 ; 56)$ & $53(47 ; 57)$ & $52(46 ; 58)$ & $53(47 ; 56)$ \\
\hline Gender (male/female) & $15 / 16$ & $16 / 15$ & $14 / 17$ & $16 / 15$ \\
\hline \multicolumn{5}{|l|}{ Education level } \\
\hline Primary school, n (\%) & $11(35.4)$ & $12(38.7)$ & $11(35.4)$ & $12(38.7)$ \\
\hline High school, n (\%) & $14(45.1)$ & $13(41.9)$ & $15(48.3)$ & $14(45.1)$ \\
\hline College/university, n (\%) & $6(19.3)$ & $6(19.3)$ & $5(16.1)$ & $5(16.1)$ \\
\hline Body mass index $\left(\mathrm{kg} / \mathrm{m}^{2}\right)$ & $24.4(21.8 ; 27.8)$ & $23.9(22.4 ; 26.4)$ & $24.8(21.6 ; 27.1)$ & $24.5(22.3 ; 26.1)$ \\
\hline Fasting glucose (mg/dl) & $87.9(82.1 ; 93.2)$ & $88.7(82.3 ; 105.3)$ & $88.1(80.6 ; 114.6)$ & $91.1(85.1 ; 109.2)$ \\
\hline Smokers, n (\%) & $2(6.4)$ & $3(9.6)$ & $2(6.4)$ & $2(9.6)$ \\
\hline Never smokers, n (\%) & $27(88.2)$ & $27(85.2)$ & $28(88.2)$ & $26(85.2)$ \\
\hline Past smokers, n (\%) & $2(6.4)$ & $1(3.2)$ & $1(3.2)$ & $3(9.6)$ \\
\hline Current smokers, n (\%) & $2(6.4)$ & $3(6.4)$ & $2(6.4)$ & $2(6.4)$ \\
\hline \multicolumn{5}{|l|}{ Comorbidities } \\
\hline Diabetes, n (\%) & - & $3(9.6) * *$ & $2(6.4)^{* *}$ & $2(9.6) * *$ \\
\hline \multicolumn{5}{|l|}{ Previous CVD } \\
\hline Atrial fibrillation, n (\%) & - & - & $6(19.3)^{* *, \S \S}$ & $5(16.1)^{* *, \S \S}$ \\
\hline Angina pectoris, $\mathrm{n}(\%)$ & - & - & $12(38.7)^{* *, \$ \S}$ & $13(41.9)^{* *, \$ \S}$ \\
\hline Stroke, n (\%) & - & - & $5(16.1)^{* *, \S \S}$ & $7(22.6) * *, \S \S$ \\
\hline Heart failure, n (\%) & - & - & $6(19.3)^{* *, \S \S}$ & $5(16.1) * *, \S \S$ \\
\hline Antihypertensive, n (\%) & - & - & $10(32.2)^{* *, \S \S}$ & $10(32.2)^{* *, \$ \S}$ \\
\hline Statins, n (\%) & - & - & $10(32.2) * *, \S \S$ & $9(29) * *, \$ \S$ \\
\hline Low-dose aspirin, n (\%) & - & - & $7(22.6)^{* *, \$ \S}$ & $7(22.6)^{* *, \S \S}$ \\
\hline Beta blockers, n (\%) & - & - & $6(19.3) * *, \S \S$ & $8(25.8) * *, \S \S$ \\
\hline hs-CRP (mg/L) & $2.5(2.1 ; 2.9)$ & $3.1(2.5 ; 3.9)^{*}$ & $5.6(4.8 ; 6.2)^{* *}$ & 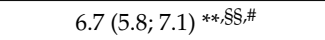 \\
\hline Total cholesterol (mg/dl) & $162(139 ; 181)$ & $164(133 ; 181)$ & $173(139 ; 197)$ & $176(178 ; 201)$ \\
\hline Triglycerids (mg/dl) & $121(91 ; 145)$ & $102(66 ; 128)$ & $141(122 ; 166)$ & $139(103 ; 158)$ \\
\hline
\end{tabular}

Compared to healthy controls, patients with periodontitis, $\mathrm{CDH}$ and a combination of periodontitis and CVD presented a higher value of hs-CRP $(p<0.001)$. Moreover, patients with CHD and periodontitis plus CHD presented no significant differences regarding past CVD events.

In Table 2 are represented dental characteristics of all enrolled patients. Compared with CHD and control patients, subjects with periodontitis and periodontitis plus CVD showed higher periodontal parameters (CAL, PD, BOP, PI) and smaller number of teeth $(p<0.001)$ (Table 2). 
Table 2. Periodontal characteristics of enrolled patients. Data are represented as median (25th; 75th percentile). CAL, clinical attachment level; PD, probing pocket depth; BOP, bleeding on probing; PI, plaque index. ${ }^{* *} p<0.001$ significant differences vs. control subjects. $\$ \S p<0.001$ significant differences vs. periodontitis patients. ${ }^{\# \#} p<0.001$ significant differences vs. CHD patients.

\begin{tabular}{|c|c|c|c|c|}
\hline & Controls $(\mathrm{N}=31)$ & Periodontitis $(\mathrm{N}=31)$ & $\begin{array}{c}\text { CVD } \\
(\mathrm{N}=31)\end{array}$ & Periodontitis + CVD $(N=31)$ \\
\hline $\mathrm{N}^{\circ}$ of teeth & $26(21 ; 27)$ & $20(15 ; 21)^{* *}$ & $23(19 ; 26)^{* *, \$ S}$ & $18(12 ; 20)^{* *, \# \#}$ \\
\hline CAL (mm) & $1(0.9 ; 1.3)$ & $3.6(3.1 ; 4.2)^{* *}$ & $2(1.8 ; 2.4) * *, \S \S$ & $3.4(3 ; 4.1) * *$,\#\# \\
\hline CAL 4-5 mm (\% sites) & - & $38.7(35.4 ; 42.9)^{* *}$ & - & $40.6(35.5 ; 46.1)^{* *, \# \#}$ \\
\hline CAL $\geq 6$ mm (\% sites $)$ & - & $18.7(19.6 ; 22.3) * *$ & - & $17.4(15.8 ; 22.7)^{* * \text { \#\# }}$ \\
\hline $\mathrm{PD}(\mathrm{mm})$ & $1.5(1.3 ; 1.9)$ & $4.4(3.7 ; 4.6)^{* *}$ & $2.1(1.8 ; 2.4)^{* *, \S \S}$ & $3.9(3.7 ; 4.4)^{* *, \# \#}$ \\
\hline PD 4-5 mm (\% sites) & - & $40.9(38.6 ; 45.7)^{* *}$ & - & 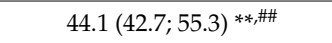 \\
\hline $\mathrm{PD} \geq 6 \mathrm{~mm}$ (\% sites) & - & $23.1(19.8 ; 25.2)^{* *}$ & - & $22.7(20.3 ; 26.5) * *, \$ \S, \# \#$ \\
\hline BOP $(\%)$ & $7.9(6.5 ; 8.3)$ & $41.2(34.3 ; 46.5)^{* *}$ & $8.1(6.4 ; 8.9)^{* *, \S \S}$ & $42.3(41.5 ; 50.1)^{* *, \$ \S, \# \#}$ \\
\hline Rx alveolar bone loss (mm) & $0.2(0.1 ; 0.5)$ & $2.9(2.5 ; 3.4)^{* *}$ & $0.3(0.2 ; 0.9)^{* *, \S \S}$ & 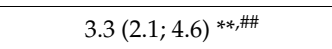 \\
\hline PI (\%) & $6.5(4.7 ; 9.3)$ & $35.4(31.7 ; 37.9) * *$ & $11.7(9.1 ; 12.8)^{* *, \$ \S}$ & $32.4(27.2 ; 36.1)^{* *, \# \#}$ \\
\hline
\end{tabular}

Figure 2 represents median (25th; 75th percentile) values of MPO levels in saliva and serum of all enrolled patients. Compared to control subjects, patients with CVD $(p<0.01)$ and with periodontitis plus CVD $(p<0.001)$ had higher median concentrations of MPO in saliva and serum. More specifically, in comparison with periodontitis subjects, patients with periodontitis plus CVD presented increased salivary and serum concentrations of MPO $(p<0.01)$ (Figure 2).
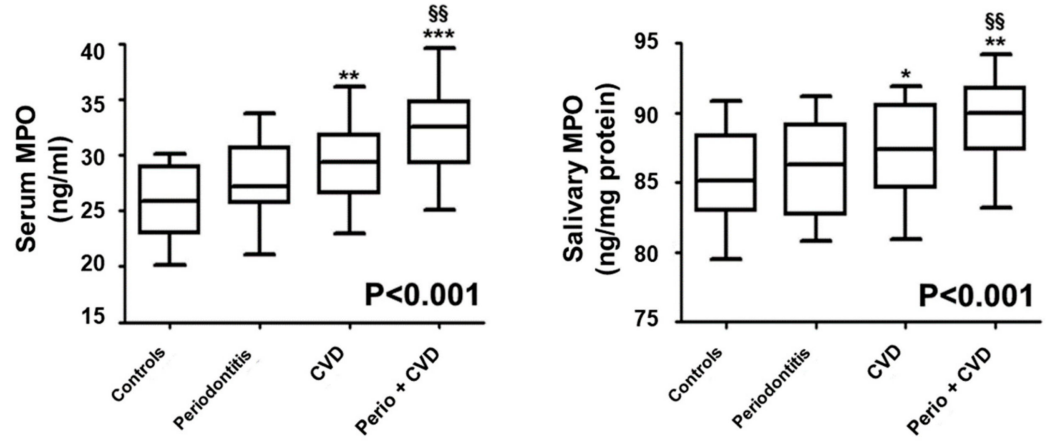

Figure 2. Median values (25\%; 75\% percentiles) of coronary heart disease (MPO) in saliva and serum. ${ }^{*} p<0.05,{ }^{* *} p<0.01$ and ${ }^{* * *} p<0.001$ significant differences vs. control subjects (derived by the Kruskal-Wallis test). $\S \S p<0.01$ significant differences vs. periodontitis patients. $p<0.001$.

Moreover, the $\mathrm{p}$-for trend analysis test evidenced that MPO in serum increased gradually in subjects with periodontitis, CVD, and with periodontitis plus CVD ( $p$-trend $<0.001$ ) (Figure 3). No statistically significant associations were found in MPO levels between serum and saliva ( $\mathrm{rs}=0.213, p=0.098$ ). Moreover, in all enrolled patients presented a positive correlation between serum/salivary MPO and hs-CRP levels ( $\mathrm{rs}=0.341, p<0.001) /(\mathrm{rs}=0.609, p<0.001)$ (Figure 3 ). 

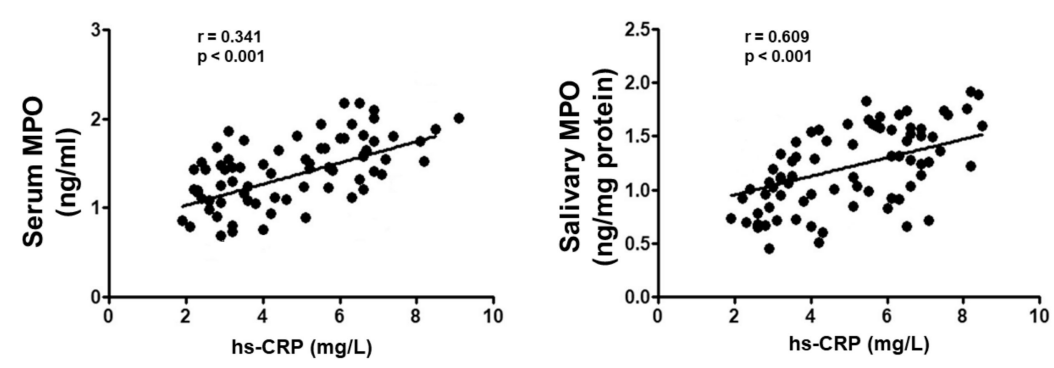

Figure 3. Analysis of correlation of serum and salivary MPO levels with c-reactive protein (CRP) in all patients.

The univariate regression analysis evidenced that there was a significant direct impact of hs-CRP on serum and salivary MPO (both $p<0.001$ ). Furthermore, the adjusted multivariate linear regression analysis evidenced that hs-CRP variable was the only significant predictor for serum MPO $(p<0.001)$.

Moreover, hs-CRP $(p<0.001)$ and total cholesterol $(p=0.035)$ were the statistically significant predictor variables for salivary MPO (Table 3).

Table 3. Uni- and multivariate linear regression analysis for MPO levels in serum and saliva in all patients. Age was included as continuous variable. For periodontitis and cardiovascular disease (CVD), controls served as reference. For gender, male served as reference.

\begin{tabular}{|c|c|c|c|c|c|c|c|}
\hline \multirow[t]{8}{*}{ Serum MPO Levels } & & \multicolumn{3}{|c|}{ UNIVARIATE } & \multicolumn{3}{|c|}{ MULTIVARIATE } \\
\hline & Variable & B & $95 \% \mathrm{CI}$ & $p$ & B & $95 \% \mathrm{CI}$ & $p$ \\
\hline & CVD & 0.442 & $0.314 ; 0.558$ & $<0.001$ & 0.122 & $-0.221 ; 0.559$ & 0.578 \\
\hline & Periodontitis & 0.289 & $0.18 ; 0.274$ & 0.024 & 0.231 & $-0.066 ; 0.319$ & 0.226 \\
\hline & hs-CRP & 0.278 & $0.028 ; 0.136$ & $<0.001$ & 0.314 & $0.065 ; 0.189$ & $<0.001$ \\
\hline & Age (years) & -0.047 & $-0.287 ; 0.056$ & 0.064 & -0.039 & $-0.111 ; 0.315$ & 0.287 \\
\hline & Female gender & 0.212 & $-0.78 ; 0.549$ & 0.227 & 0.219 & $-0.88 ; 0.428$ & 0.112 \\
\hline & Education SES & -0.114 & $-0.178 ; 0.123$ & 0.287 & -0.066 & $-0.312 ; 0.398$ & 0.312 \\
\hline \multicolumn{8}{|l|}{ Salivary MPO Levels } \\
\hline & CVD & 0.319 & $0.112 ; 0.552$ & $<0.001$ & -0.065 & $-0.412 ; 0.289$ & 0.451 \\
\hline & Periodontitis & 0.078 & $-0.069 ; 0.328$ & 0.411 & 0.007 & $-0.178 ; 0.213$ & 0.665 \\
\hline & hs-CRP & 0.082 & $0.027 ; 0.287$ & $<0.001$ & 0.066 & $0.021 ; 0.133$ & $<0.001$ \\
\hline & Age (years) & -0.051 & $-0.110 ; 0.036$ & 0.399 & 0.047 & $-0.028 ; 0.087$ & 0.741 \\
\hline & Female gender & 0.074 & $-0.112 ; 0.211$ & 0.398 & 0.071 & $-0.065 ; 0.412$ & 0.321 \\
\hline & Total Cholesterol & -0.057 & $-0.151 ;-0.062$ & 0.037 & -0.65 & $-0.041 ; 0.314$ & 0.035 \\
\hline & Serum MPO & 0.122 & $-0.021 ; 0.557$ & 0.057 & -0.036 & $-0.369 ; 0.166$ & 0.331 \\
\hline
\end{tabular}

\section{Discussion}

This trial was aimed at evaluating the impact of conditions such as periodontal disease, CVD, or periodontitis plus CVD on MPO levels in serum and saliva. The present trial evidenced that the occurrence of CVD caused increased levels of MPO and hs-CRP in serum and saliva. Nevertheless, in comparison with periodontitis and healthy controls, only the group of subjects with CVD and periodontitis plus CVD had significantly elevated MPO levels in serum and saliva, endorsing the suggestion that CVD influenced the increment of MPO levels in serum and saliva. Furthermore, results of the present study show that the simultaneous presence of periodontitis in patients with CVD can determine an increased activation of MPO and therefore represent a subclinical stimulus for the purpose of an increase in CVD development.

In accordance with the results of the present study, some reports have shown that high levels of MPO in serum represent real independent risk factors of CVD development and increased mortality index, possibly by inactivating NO signaling [33]. Specifically, it has also been shown that, in patients with atherosclerosis, high systemic levels of $\mathrm{MPO}$ are associated with significant carotid epithelial dysfunctions, underlining the fundamental inhibitory role of NO exercised by MPO [34]. 
Therefore, the simultaneous presence of CVD on the one hand and periodontitis on the other hand can be a real explanation for the deterioration of endothelial function due to high levels of MPO. In this regard, recent research has shown that the treatment of periodontitis has significantly reduced the systemic levels of MPO in patients with coronary disease [35].

Moreover, several reports demonstrated that increased hs-CRP levels in serum can facilitate the increment of MPO levels in serum in several diseases in humans [23,35-38]. In accordance with the results of our study, several studies have been demonstrated that situations which may cause an increase of oxidative stress, such as CVD and periodontal disease, cause the high release of CRP, which in turn, can arouse the production of MPO in saliva and serum in order to defend tissue damage determined by oxidative stress condition [36]. In agreement with the results of the present study, Magan-Fernandez et al. [39] demonstrated that CRP and MPO levels were higher during active phases of periodontal disease.

However, while evidence has previously been demonstrated regarding high serum MPO levels as primary mediators of endothelial dysfunction or in the development of cardiovascular risk, from the authors' knowledge, there is no specific evidence to determine MPO levels in saliva in order to evaluate whether the increased expression of salivary MPO levels determines, by reflection, an increase in MPO in serum and then analyzes the salivary levels of MPO as an index of endothelial dysfunction. In this regard, however, it should be noted that this study did not reveal a significant correlation between serum and saliva MPO levels, as salivary MPO levels are influenced in patients enrolled independently only of hs-CRP and total cholesterol. This explanation can be determined by the way that MPO salivary levels may be due to an exclusive local oral production of MPO.

In this regard, it should be noted that, from the studies currently present in the literature, while the effect of MPO at a systemic level mediated by the reduction of NO on endothelial damage has been previously highlighted, the impact of MPO activation orally (e.g., in saliva) is less clear. However, there are studies that show that periodontal disease is positively correlated with high levels of NO and therefore with related stress-oxidative damage [19,24]. The presence of high levels of $\mathrm{NO}$ at salivary level can be explained as NO is produced orally in response by the host as a specific salivary defense in the presence of periodontal pathogenic bacteria that are exacerbated during periodontitis $[12,24,40]$. Furthermore, some studies suggested that decreasing activities of NO and some other enzymatic antioxidants, such as superoxide dismutase catalase, were associated with periodontitis and high levels of MPO, whereas others claim that antioxidants function as protective agents against free radicals during $C P$ progression $[19,24,41]$.

However, there is no unanimous consensus in the literature on the effects of NO levels on tissue damage during periodontitis. Some reports have shown high levels of NO in periodontal tissue in the active periodontal period $[39,42]$ while, on the other hand, other authors have shown lower levels of NO in saliva of subjects with periodontal disease $[25,43]$. However, results in the literature may have been determined by the different homogeneity of the patients enrolled in the studies, by the different age ranges of the patients analyzed, or by the excessive presence of patients who smoke; in fact it has been shown that smoking can cause a high increase in salivary NO salivary levels [44-46]. Another explanation for the different results found in the literature can be determined by the different salivary sampling method performed in the different studies. Furthermore, the cause of the different expression of MPO at the salivary and serum level may be due to a different production of NO at the oral level which may be different from the serum one.

As an explanation of the results of the present study, it should be highlighted that the dysfunctional damage at the endothelium level found in patients with periodontitis and with CVD can be determined by a specific inflammatory and immune pathway in which MPO modulates a response towards pathogenic bacteria of the oral biofilm which are exacerbated during the active phases of periodontal damage. It has also been shown that MPO, during periodontal disease, mediates the immune response at the endothelial level through specific heat shock proteins which has been shown to be useful for stimulating the production of cross-reactive T cells [47-52]. In this regard, this process which sees 
MPO as a key modulator [53-58], has also been shown to influence the host defense mechanism that determines a subsequent activation of endothelial cell production $[55,58-63]$ which leads to an increased risk of future tissue damage effects due to periodontal pathogens bacteria in several oral diseases [43,64-68]. Moreover, the oral microbiota is a key factor in the protection against the colonization of extrinsic pathogens that could impact systemic health [68]. However, the imbalance of the ecosystem together with high levels of MPO, which can be caused by a weak immune system, lead to a challenge for oral and systemic health [68]. The ecological conditions of these habitats are constantly changing, so ecosystems are subject to frequent variations $[68,69]$.

However, the present trial has some limitations. Among the main limitations there is the type of study, which makes it difficult to analyze the cause and effect on a temporal level of MPO. The small sample size, due to high inclusion and exclusion levels, and to the important excluded confounders, also represents a limitation of the present preliminary study. However, the exclusion of several confounders represents a positive and rigorous aspect for the clear evaluation of these confounders on the concentration of serum and salivary levels of MPO.

Recently, different approaches have been developed with the aim of easily evaluating innovative salivary markers useful for early and subclinically validating the development of different diseases. This study indicates that patients suffering from periodontitis and CVD have higher serum and salivary levels of MPO than subjects with periodontitis and healthy subjects.

The results of this study propose that mostly CVD is a stimulus to the increased serum MPO levels which may be beyond a pathway intermediated by hs-CRP. Therefore, these results are promising but at the same time require further studies with a larger sample of analysis in order to better comprehend the function of MPO during periodontitis.

Author Contributions: Conceptualization, A.P.; methodology, S.T.; validation, S.S., formal analysis, M.D.S.; writing-original draft preparation, F.I.; A.L.G. All authors have read and agreed to the published version of the manuscript.

Funding: This research received no external funding.

Conflicts of Interest: The authors declare no conflict of interest.

\section{References}

1. Tonetti, M.S.; Greenwell, H.; Kornman, K.S. Staging and grading of periodontitis: Framework and proposal of a new classification and case definition. J. Periodontol. 2018, 89 (Suppl. 1), S159-S172. [CrossRef] [PubMed]

2. Briguglio, F.; Briguglio, E.; Briguglio, R.; Cafiero, C.; Isola, G. Treatment of infrabony periodontal defects using a resorbable biopolymer of hyaluronic acid: a randomized clinical trial. Quintessence Int. 2013, 44, 231-240. [PubMed]

3. Eke, P.I.; Wei, L.; Thornton-Evans, G.O.; Borrell, L.N.; Borgnakke, W.S.; Dye, B.; Genco, R.J. Risk Indicators for Periodontitis in US Adults: NHANES 2009 to 2012. J. Periodontol. 2016, 87, 1174-1185. [CrossRef] [PubMed]

4. Isola, G.; Alibrandi, A.; Currò, M.; Matarese, M.; Ricca, S.; Matarese, G.; Ientile, R.; Kocher, T. Evaluation of salivary and serum ADMA levels in patients with periodontal and cardiovascular disease as subclinical marker of cardiovascular risk. J. Periodontol. 2020. [CrossRef]

5. Isola, G.; Giudice, A.L.; Polizzi, A.; Alibrandi, A.; Patini, R.; Ferlito, S. Periodontitis and Tooth Loss Have Negative Systemic Impact on Circulating Progenitor Cell Levels: a Clinical Study. Genes 2019, 10, 1022. [CrossRef]

6. Holmlund, A.; Holm, G.; Lind, L. Number of Teeth as a Predictor of Cardiovascular Mortality in a Cohort of 7,674 Subjects Followed for 12 Years. J. Periodontol. 2010, 81, 870-876. [CrossRef]

7. Isola, G.; Polizzi, A.; Alibrandi, A.; Indelicato, F.; Ferlito, S. Analysis of Endothelin-1 concentrations in individuals with periodontitis. Sci. Rep. 2020. [CrossRef]

8. Li, C.; Lv, Z.; Shi, Z.; Zhu, Y.; Wu, Y.; Li, L.; Iheozor-Ejiofor, Z. Periodontal therapy for the management of cardiovascular disease in patients with chronic periodontitis. Cochrane Database Syst. Rev. 2017, 2017, CD009197. [CrossRef]

9. Isola, G.; Polizzi, A.; Muraglie, S.; Leonardi, R.; Giudice, A.L. Assessment of Vitamin C and Antioxidant Profiles in Saliva and Serum in Patients with Periodontitis and Ischemic Heart Disease. Nutrients 2019, 11, 2956. [CrossRef] 
10. Matarese, G.; Curro, M.; Isola, G.; Caccamo, D.; Vecchio, M.; Giunta, M.L.; Ramaglia, L.; Cordasco, G.; Williams, R.C.; Ientile, R. Transglutaminase 2 up-regulation is associated with RANKL/OPG pathway in cultured HPDL cells and THP-1-differentiated macrophages. Amino Acids 2015, 47, 2447-2455. [CrossRef]

11. Aratani, Y. Myeloperoxidase: Its role for host defense, inflammation, and neutrophil function. Arch. Biochem. Biophys. 2018, 640, 47-52. [CrossRef] [PubMed]

12. Ahmad, S.; Ramadori, G.; Moriconi, F. Modulation of Chemokine- and Adhesion-Molecule Gene Expression and Recruitment of Neutrophil Granulocytes in Rat and Mouse Liver after a Single Gadolinium Chloride or Zymosan Treatment. Int. J. Mol. Sci. 2018, 19, 3891. [CrossRef] [PubMed]

13. de Souza, R.G.M.; Gomes, A.C.; Navarro, A.M.; Cunha, L.C.D.; Silva, M.A.C.; Junior, F.B.; Mota, J.F. Baru Almonds Increase the Activity of Glutathione Peroxidase in Overweight and Obese Women: a Randomized, Placebo-Controlled Trial. Nutrients 2019, 11, 1750. [CrossRef] [PubMed]

14. Isola, G.; Matarese, G.; Giudice, G.L.; Briguglio, F.; Alibrandi, A.; Crupi, A.; Cordasco, G.; Ramaglia, L. a New Approach for the Treatment of Lateral Periodontal Cysts with an 810-nm Diode Laser. Int. J. Periodontics Restor. Dent. 2017, 37, 120-129. [CrossRef] [PubMed]

15. Matarese, G.; Isola, G.; Anastasi, G.P.; Cutroneo, G.; Favaloro, A.; Vita, G.; Cordasco, G.; Milardi, D.; Zizzari, V.L.; Tetè, S.; et al. Transforming Growth Factor Beta 1 and Vascular Endothelial Growth Factor levels in the pathogenesis of periodontal disease. Eur. J. Inflamm. 2013, 11, 479-488. [CrossRef]

16. Peniche-Palma, D.C.; Carrillo-Avila, B.A.; Sauri-Esquivel, E.A.; Acosta-Viana, K.; Esparza-Villalpando, V.; Pozos-Guillen, A.; Hernandez-Rios, M.; Martinez-Aguilar, V.M. Levels of Myeloperoxidase and Metalloproteinase-9 in Gingival Crevicular Fluid from Diabetic Subjects with and without Stage 2, Grade B Periodontitis. BioMed Res. Int. 2019, 2019, 5613514. [CrossRef]

17. Currò, M.; Matarese, G.; Isola, G.; Caccamo, D.; Ventura, V.P.; Cornelius, C.; Lentini, M.; Cordasco, G.; Ientile, R. Differential expression of transglutaminase genes in patients with chronic periodontitis. Oral Dis. 2014, 20, 616-623. [CrossRef]

18. Isola, G.; Williams, R.C.; Lo Gullo, A.; Ramaglia, L.; Matarese, M.; Iorio-Siciliano, V.; Cosio, C.; Matarese, G. Risk association between scleroderma disease characteristics, periodontitis, and tooth loss. Clin Rheumatol. 2017, 36, 2733-2741. [CrossRef]

19. Andrukhov, O.; Haririan, H.; Bertl, K.; Rausch, W.-D.; Bantleon, H.-P.; Moritz, A.; Rausch-Fan, X. Nitric oxide production, systemic inflammation and lipid metabolism in periodontitis patients: Possible gender aspect. J. Clin. Periodontol. 2013, 40, 916-923. [CrossRef]

20. Isola, G.; Alibrandi, A.; Rapisarda, E.; Matarese, G.; Williams, R.C.; Leonardi, R. Association of vitamin d in patients with periodontitis: a cross-sectional study. J. Periodontal Res. 2020, in press.

21. Gurav, A.N. The implication of periodontitis in vascular endothelial dysfunction. Eur. J. Clin. Investig. 2014, 44, 1000-1009. [CrossRef]

22. Tabeta, K.; Hosojima, M.; Nakajima, M.; Miyauchi, S.; Miyazawa, H.; Takahashi, N.; Matsuda, Y.; Sugita, N.; Komatsu, Y.; Sato, K.; et al. Increased serum PCSK9, a potential biomarker to screen for periodontitis, and decreased total bilirubin associated with probing depth in a Japanese community survey. J. Periodontal Res. 2018, 53, 446-456. [CrossRef]

23. Isola, G.; Ramaglia, L.; Cordasco, G.; Lucchese, A.; Fiorillo, L.; Matarese, G. The effect of a functional appliance in the management of temporomandibular joint disorders in patients with juvenile idiopathic arthritis. Minerva Stomatol. 2017, 66, 1-8. [PubMed]

24. Kendall, H.K.; Marshall, R.I.; Bartold, P.M. Nitric oxide, and tissue destruction. Oral Dis. 2001, 7, 2-10. [CrossRef] [PubMed]

25. Aurer, A.; Aleksic, J.; Ivic-Kardum, M.; Aurer, J.; Čulo, F. Nitric oxide synthesis is decreased in periodontitis. J. Clin. Periodontol. 2001, 28, 565-568. [CrossRef] [PubMed]

26. Ruest, L.B.; Ranjbaran, H.; Tong, E.J.; Svoboda, K.K.H.; Feng, J.Q. Activation of Receptor Activator of Nuclear Factor- $\mathrm{kB}$ Ligand and Matrix Metalloproteinase Production in Periodontal Fibroblasts by Endothelin Signaling. J. Periodontol. 2016, 87, e1-e8. [CrossRef] [PubMed]

27. von Elm, E.; Altman, D.G.; Egger, M.; Pocock, S.J.; Gotzsche, P.C.; Vandenbroucke, J.P. The Strengthening the Reporting of Observational Studies in Epidemiology (STROBE) statement: Guidelines for reporting observational studies. J. Clin. Periodontol. 2008, 61, 344-349. [CrossRef]

28. Lindhe, J.; Ranney, R.; Lamster, I.; Charles, A.; Chung, C.-P.; Flemmig, T.; Kinane, D.; Listgarten, M.; Löe, H.; Schoor, R.; et al. Consensus Report: Chronic Periodontitis. Ann. Periodontol. 1999, 4, 38. [CrossRef] 
29. Isola, G.; Matarese, M.; Ramaglia, L.; Iorio-Siciliano, V.; Cordasco, G.; Matarese, G. Efficacy of a drug composed of herbal extracts on postoperative discomfort after surgical removal of impacted mandibular third molar: a randomized, triple-blind, controlled clinical trial. Clin. Oral Investig. 2019, 23, 2443-2453. [CrossRef]

30. Bassand, J.P.; Hamm, C.W.; Ardissino, D.; Boersma, E.; Budaj, A.; Fernández-Avilés, F.; Fox, K.A.; Hasdai, D.; Ohman, E.M.; Wallentin, L.; et al. Guidelines for the diagnosis and treatment of non-ST-segment elevation acute coronary syndromes: The Task Force for the Diagnosis and Treatment of Non-ST-Segment Elevation Acute Coronary Syndromes of the European Society of Cardiology. Eur. Heart J. 2007, 28, 1598-1660. [CrossRef]

31. O'Leary, T.J.; Drake, R.B.; Naylor, J.E. The Plaque Control Record. J. Periodontol. 1972, 43, 38. [CrossRef] [PubMed]

32. Hollander, M.; Wolfe, D.A.; Chicken, E. Nonparametric Statistical Methods, 3rd ed.; John Wiley \& Sons: Hoboken, NJ, USA, 2013.

33. Lo Giudice, G.; Lo Giudice, R.; Matarese, G.; Isola, G.; Cicciù, M.; Terranova, A.; Palaia, G.; Romeo, U. Evaluation of magnification systems in restorative dentistry. An in-vitro study. Dental Cadmos 2015, 83, 296-305. [CrossRef]

34. Mazzoli, A.; Crescenzo, R.; Cigliano, L.; Spagnuolo, M.S.; Cancelliere, R.; Gatto, C.; Iossa, S. Early Hepatic Oxidative Stress and Mitochondrial Changes Following Western Diet in Middle Aged Rats. Nutrients 2019, 11, 2670. [CrossRef]

35. Lahdentausta, L.; Paju, S.; Mäntylä, P.; Buhlin, K.; Pietiäinen, M.; Tervahartiala, T.; Nieminen, M.S.; Sinisalo, J.; Sorsa, T.; Pussinen, P.J. Smoking confounds the periodontal diagnostics using saliva biomarkers. J. Periodontol. 2019, 90, 475-483. [CrossRef]

36. Isola, G.; Matarese, G.; Ramaglia, L.; Pedullà, E.; Rapisarda, E.; Iorio-Siciliano, V. Association between periodontitis and glycosylated haemoglobin before diabetes onset: a cross-sectional study. Clin. Oral Investig. 2019. [CrossRef]

37. Valenzuela, M.; Draibe, J.; Quero, M.; Fulladosa, X.; Cruzado, J.M.; Bestard, O.; Torras, J.; Valenzuela, L.M. Exploring Frequencies of Circulating Specific Th17 Cells against Myeloperoxidase and Proteinase 3 in ANCA Associated Vasculitis. Int. J. Mol. Sci. 2019, 20, 5820. [CrossRef]

38. Przepiera-Będzak, H.; Fischer, K.; Brzosko, M. Serum Interleukin-18, Fetuin-A, Soluble Intercellular Adhesion Molecule-1, and Endothelin-1 in Ankylosing Spondylitis, Psoriatic Arthritis, and SAPHO Syndrome. Int. J. Mol. Sci. 2016, 17, 1255. [CrossRef]

39. Magán-Fernández, A.; O’Valle, F.; Abadía-Molina, F.; Muñoz, R.; Puga-Guil, P.; Mesa, F. Characterization and comparison of neutrophil extracellular traps in gingival samples of periodontitis and gingivitis: a pilot study. J. Periodontal Res. 2019, 54, 218-224. [CrossRef]

40. Cavuoti, S.; Matarese, G.; Isola, G.; Abdolreza, J.; Femiano, F.; Perillo, L. Combined orthodontic-surgical management of a transmigrated mandibular canine: a case report. Angle Orthod. 2016, 86, 681-691. [CrossRef]

41. Matejka, M.; Partyka, L.; Ulm, C.; Solar, P.; Sinzinger, H. Nitric oxide synthesis is increased in periodontal disease. J. Periodontal Res. 1998, 33, 517-518. [CrossRef]

42. Perillo, L.; Isola, G.; Esercizio, D.; Iovane, M.; Triolo, G.; Matarese, G. Differences in craniofacial characteristics in Southern Italian children from Naples: a retrospective study by cephalometric analysis. Eur. J. Paediatr. Dent. 2013, 14, 195-198. [PubMed]

43. Ozer, L.; Elgün, S.; Özdemir, B.; Pervane, B.; Özmeriç, N. Arginine-Nitric Oxide-Polyamine Metabolism in Periodontal Disease. J. Periodontol. 2011, 82, 320-328. [CrossRef]

44. Bodis, S.; Haregewoin, A. Significantly reduced salivary nitric oxide levels in smokers. Ann. Oncol. 1994, 5, $371-372$. [CrossRef]

45. Vasconcelos, D.F.P.; Da Silva, F.R.P.; Pinto, M.E.S.C.; Santana, L.D.A.B.; Souza, I.G.; De Souza, L.K.M.; Oliveira, N.C.M.; Ventura, C.A.; Novaes, P.D.; Barbosa, A.L.D.R.; et al. Decrease of Pericytes is Associated with Liver Disease Caused by Ligature-Induced Periodontitis in Rats. J. Periodontol. 2017, 88, e49-e57. [CrossRef] [PubMed]

46. Isola, G.; Polizzi, A.; Santonocito, S.; Alibrandi, A.; Ferlito, S. Expression of Salivary and Serum Malondialdehyde and Lipid Profile of Patients with Periodontitis and Coronary Heart Disease. Int. J. Mol. Sci. 2019, 20, 6061. [CrossRef] [PubMed]

47. Isola, G.; Matarese, M.; Ramaglia, L.; Cicciù, M.; Matarese, G. Evaluation of the efficacy of celecoxib and ibuprofen on postoperative pain, swelling, and mouth opening after surgical removal of impacted third 
molars: a randomized, controlled clinical trial. Int. J. Oral Maxillofac. Surg. 2019, 48, 1348-1354. [CrossRef] [PubMed]

48. Isola, G.; Perillo, L.; Migliorati, M.; Matarese, M.; Dalessandri, D.; Grassia, V.; Alibrandi, A.; Matarese, G. The impact of temporomandibular joint arthritis on functional disability and global health in patients with juvenile idiopathic arthritis. Eur. J. Orthod. 2019, 41, 117-124. [CrossRef]

49. Isola, G.; Anastasi, G.P.; Matarese, G.; Williams, R.C.; Cutroneo, G.; Bracco, P.; Piancino, M.G. Functional and molecular outcomes of the human masticatory muscles. Oral Dis. 2018, 24, 1428-1441. [CrossRef]

50. Isola, G.; Alibrandi, A.; Pedullà, E.; Grassia, V.; Ferlito, S.; Perillo, L.; Rapisarda, E. Analysis of the Effectiveness of Lornoxicam and Flurbiprofen on Management of Pain and Sequelae Following Third Molar Surgery: a Randomized, Controlled, Clinical Trial. J. Clin. Med. 2019, 8, 325. [CrossRef]

51. Camacho-Alonso, F.; Davia-Peña, R.S.; Vilaplana-Vivo, C.; Tudela-Mulero, M.R.; Merino, J.J.; Martínez-Beneyto, Y. Synergistic effect of photodynamic therapy and alendronate on alveolar bone loss in rats with ligature-induced periodontitis. J. Periodontal Res. 2017, 53, 306-314. [CrossRef]

52. Isola, G.; Matarese, G.; Alibrandi, A.; Dalessandri, D.; Migliorati, M.; Pedullà, E.; Rapisarda, E. Comparison of Effectiveness of Etoricoxib and Diclofenac on Pain and Perioperative Sequelae After Surgical Avulsion of Mandibular Third Molars: a Randomized, Controlled, Clinical Trial. Clin. J. Pain 2019, 35, 908-915. [CrossRef]

53. Mohammed, H.; Varoni, E.M.; Cochis, A.; Cordaro, M.; Gallenzi, P.; Patini, R.; Staderini, E.; Lajolo, C.; Rimondini, L.; Rocchetti, V. Oral Dysbiosis in Pancreatic Cancer and Liver Cirrhosis: a Review of the Literature. Biomedicines 2018, 6, 115. [CrossRef] [PubMed]

54. Patini, R.; Gallenzi, P.; Spagnuolo, G.; Cordaro, M.; Cantiani, M.; Amalfitano, A.; Arcovito, A.; Callà, C.; Mingrone, G.; Nocca, G. Correlation Between Metabolic Syndrome, Periodontitis and Reactive Oxygen Species Production. a Pilot Study. Open Dent. J. 2017, 11, 621-627. [CrossRef]

55. Caccianiga, G.; Paiusco, A.; Perillo, L.; Nucera, R.; Pinsino, A.; Maddalone, M.; Cordasco, G.; Giudice, A.L. Does Low-Level Laser Therapy Enhance the Efficiency of Orthodontic Dental Alignment? Results from a Randomized Pilot Study. Photomed. Laser Surg. 2017, 35, 421-426. [CrossRef] [PubMed]

56. Lo Giudice, A.; Nucera, R.; Leonardi, R.; Paiusco, A.; Baldoni, M.; Caccianiga, G. a Comparative Assessment of the Efficiency of Orthodontic Treatment with and Without Photobiomodulation during Mandibular Decrowding in Young Subjects: a Single-Center, Single-Blind Randomized Controlled Trial. Photobiomodul. Photomed. Laser Surg. 2020. [CrossRef]

57. Ferlazzo, N.; Currò, M.; Zinellu, A.; Caccamo, D.; Isola, G.; Ventura, V.; Carru, C.; Matarese, G.; Ientile, R. Influence of MTHFR genetic background on P16 and MGMT methylation in oral squamous cell cancer. Int. J. Mol. Sci. 2017, 18, 724. [CrossRef]

58. Cutroneo, G.; Piancino, M.G.; Ramieri, G.; Bracco, P.; Vita, G.; Isola, G.; Vermiglio, G.; Favaloro, A.; Anastasi, G.P.; Trimarchi, F. Expression of muscle-specific integrins in masseter muscle fibers during malocclusion disease. Int. J. Mol. Med. 2012, 30, 235-242. [CrossRef]

59. Isola, G.; Matarese, M.; Briguglio, F.; Grassia, V.; Picciolo, G.; Fiorillo, L.; Matarese, G. Effectiveness of Low-Level Laser Therapy during Tooth Movement: a Randomized Clinical Trial. Materials 2019, 12, 2187. [CrossRef]

60. Piancino, M.G.; Isola, G.; Cannavale, R.; Cutroneo, G.; Vermiglio, G.; Bracco, P.; Anastasi, G.P.; Grazia, P.M.; Gaetano, I.; Rosangela, C.; et al. From periodontal mechanoreceptors to chewing motor control: a systematic review. Arch. Oral Boil. 2017, 78, 109-121. [CrossRef]

61. Lo Giudice, A.; Nucera, R.; Perillo, L.; Paiusco, A.; Caccianiga, G. Is low-level laser therapy an effective method to alleviate pain induced by active orthodontic alignment archwire? a randomized clinical trial. J. Evid. Based Dent. Pract. 2019, 19, 71-78. [CrossRef]

62. Leonardi, R.; Lo Giudice, A.; Rugeri, M.; Muraglie, S.; Cordasco, G.; Barbato, E. Three-dimensional evaluation on digital casts of maxillary palatal size and morphology in patients with functional posterior crossbite. Eur. J. Orthod. 2018, 40, 556-562. [CrossRef] [PubMed] 
63. Giudice, A.L.; Caccianiga, G.; Crimi, S.; Cavallini, C.; Leonardi, R. Frequency and type of ponticulus posticus in a longitudinal sample of nonorthodontically treated patients: Relationship with gender, age, skeletal maturity, and skeletal malocclusion. Oral Surg. Oral Med. Oral Pathol. Oral Radiol. 2018, 126, 291-297. [CrossRef] [PubMed]

64. Cannavale, R.; Matarese, G.; Isola, G.; Grassia, V.; Perillo, L. Early treatment of an ectopic premolar to prevent molar-premolar transposition. Am. J. Orthod. Dentofacial Orthop. 2013, 143, 559-569. [CrossRef] [PubMed]

65. Matarese, G.; Isola, G.; Alibrandi, A.; Lo Gullo, A.; Bagnato, G.; Cordasco, G.; Perillo, L. Occlusal and MRI characterizations in systemic sclerosis patients: a prospective study from Southern Italian cohort. Joint. Bone. Spine. 2016, 83, 57-62. [CrossRef] [PubMed]

66. Isola, G.; Matarese, G.; Cordasco, G.; Rotondo, F.; Crupi, A.; Ramaglia, L. Anticoagulant therapy in patients undergoing dental interventions: a critical review of the literature and current perspectives. Minerva Stomatol. 2015, 64, 21-46. [PubMed]

67. Matarese, G.; Isola, G.; Ramaglia, L.; Dalessandri, D.; Lucchese, A.; Alibrandi, A.; Fabiano, F.; Cordasco, G. Periodontal biotype: characteristic, prevalence and dimensions related to dental malocclusion. Minerva Stomatol. 2016, 65, 231-238.

68. Bourgeois, D.; Inquimbert, C.; Ottolenghi, L.; Carrouel, F. Periodontal Pathogens as Risk Factors of Cardiovascular Diseases, Diabetes, Rheumatoid Arthritis, Cancer, and Chronic Obstructive Pulmonary Disease-Is There Cause for Consideration? Microorganisms 2019, 7, 424. [CrossRef]

69. Khan, A.A.; Alsahli, M.A.; Rahmani, A.H. Myeloperoxidase as an Active Disease Biomarker: Recent Biochemical and Pathological Perspectives. Med. Sci. 2018, 6, 33. [CrossRef]

(C) 2020 by the authors. Licensee MDPI, Basel, Switzerland. This article is an open access article distributed under the terms and conditions of the Creative Commons Attribution (CC BY) license (http://creativecommons.org/licenses/by/4.0/). 